\title{
Hands up for free wi-fi across the NHS
}

\author{
Fiona Godlee editor in chief, The BMJ
}

Financial pressure on the NHS in England continues to grow, with two thirds of trusts predicting a deficit at the end of 2015-16, up from 25\% last year (doi:10.1136/bmj.h3670), and a predicted overall deficit of nearly $£ 30 \mathrm{bn}$ by 2020 . All of which translates into the steady erosion of patient care and staff morale.

New thinking is needed, although not of the sort that led the health secretary to propose printing the indicative cost of drugs on packs worth more than $£ 20$, alongside the phrase "funded by the UK tax payer" (doi:10.1136/bmj.h3637). The BMJ's sister journal the Drug and Therapeutics Bulletin rightly called this a headline grabbing gimmick that would worry vulnerable patients, with no evidence that it would improve compliance or reduce costs (doi:10.1136/dtb.2015.8.0341). Seven day working is the latest political demand, but how this will be resourced remains unclear.

I can't resist pointing out again the huge waste of money, time, and energy wreaked by the 2012 Health and Social Care Act.

Similarly damaging, the private finance initiative (PFI) continues to take its toll. As Mark Hellowell explains, two thirds of NHS trusts with a deficit of more than $£ 25 \mathrm{~m}$ have a PFI deal (doi:10. 1136/bmj.h4030). One NHS trust has managed to terminate its PFI agreement. Having paid $£ 67 \mathrm{~m}$ over 10 years for a hospital with a capital value of $£ 54 \mathrm{~m}$, the trust borrowed $£ 114 \mathrm{~m}$ from the county council to end the contract. This will bring long term savings, prompting Hellowell to call for a coordinated approach from central government to help trusts extricate themselves from these extortionate arrangements. As he says, trusts that are under the most serious financial pressures are the least likely to be able to buy themselves out.
In such hard times, where on the list of competing demands should we place proposals for free wi-fi in all NHS premises? Low down, says Grant Ingrams (doi:10.1136/bmj.h4098) in our Head to Head debate this week. It would be unethical to divert money from frontline clinical services, he thinks. Other digital improvements should take precedence, such as upgrading the primary care IT system.

Ingrams has other concerns too. Members of the public will come in and use the free wi-fi, patients will be distracted and clinics will run even later, and inappropriate use would have to be controlled, with costs of filtering and legal liabilities. Yet as Victoria Betton points out (doi:10.1136/bmj.h4098), some hospitals have already installed free wi-fi. She says that it would result in a better experience among patients and possibly better outcomes, as people are able to continue their everyday interactivity while they lie in bed or wait in a casualty department or clinic. Please share your experiences in a rapid response to the article. Have you encountered the problems listed by Ingram? Or are you seeing the benefits that Betton predicts?

There's no mention of the actual cost of installing free wi-fi across the NHS. Without this it's hard to come to a view on the value. Who knows: free wi-fi could be as important as seven day working and is almost certainly easier to deliver in the short term.

Cite this as: BMJ 2015;351:h4384

(๑) BMJ Publishing Group Ltd 2015 